\title{
CONTINUOUS PRODUCTIVE URBAN LANDSCAPE (CPUL): Essential Infrastructure and Edible Ornament
}

\section{Andre Viljoen \& Katrin Bohn}

\begin{abstract}
This paper defines Continuous Productive Urban Landscape (CPUL) as a strategy for the coherent integration of urban agriculture into urban space planning. The case is made for considering urban agriculture as an essential element of sustainable infrastructure.

Recent and historic arguments are used to support the qualitative and quantifiable advantages of introducing urban agriculture into contemporary open urban space design.

The body of the paper focuses on design issues related to the placing and perception of CPUL and urban agriculture. It draws on primary research undertaken in Cuba, considering Cuba as a laboratory for design research into urban agriculture.

Design studies by the authors are used to demonstrate the viability and physical manifestation of urban agriculture within a Continuous Productive Urban Landscape. The paper proposes that, while an environmental and design case can be made for the integration of urban agriculture, planners and designers need to explore the public perception of productive landscape if its full potential is to be realized.

The idea that urban agriculture can be read as "ornament" is discussed with reference to the writing of British artist Tom Phillips. Contemporary cultural/artistic practice is referred to as a means for exploring and communicating ideas related to productive urban landscapes.

The paper concludes with new research findings related to the public perception of open urban space based on the Havana CPUL design research project "Finding Parque Lenin".
\end{abstract}

Keywords: Urban Design, Productive Landscapes, Sustainable Systems, CPUL, Urban Agriculture.

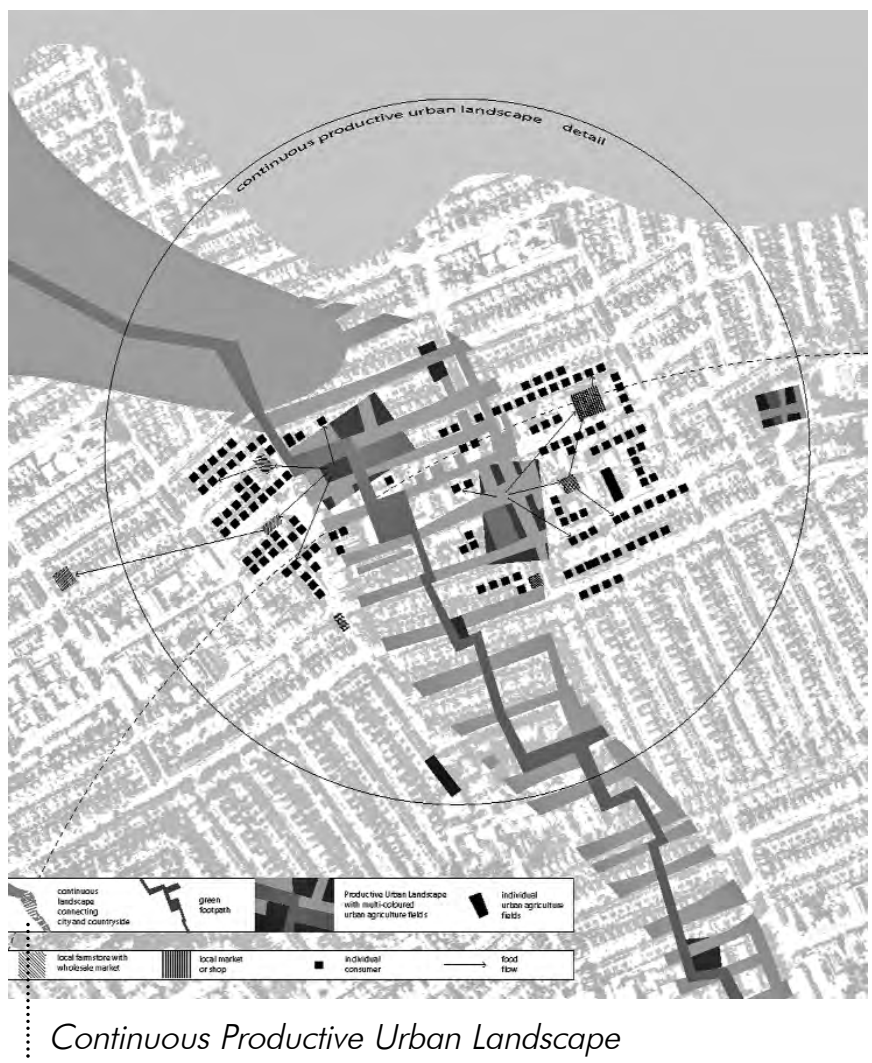




\section{CONTINUOUS PRODUCTIVE URBAN LANDSCAPE : DESIGNING FOR URBAN AGRICULTURE}

Our interest in urban agriculture grew out of connections made between three ideas emerging during the 1990ies. One was the design debate focusing on infrastructure, exemplified by the notion of infrastructural urbanism (Allen 1996), the second was our interest in reducing the environmental impact of architecture, influenced by ecological footprint research (Wackernagel and Rees 1996), and the third was the revived discussion about public open space which confirmed urban landscape as major contextual and lifestyle component for the design of a sustainable contemporary city (Yokohari et al. 1995).

Allen's studies from the 1990ies, referring to the patchy nature of cities, prompted the idea that agriculture could fit into the contemporary urban fabric. Our intuition suggested that urban agriculture could contribute positively to the creation of sustainable cities, while not compromising the urbanity and sustainable benefits of a compact city. We therefore developed a two-strand approach to test this intuition. On one side, we investigated the literature to try and quantify the reductions in embodied energy and $\mathrm{CO} 2$ emissions associated with organic urban agriculture. The other side of our work took the form of design research, in which we used architectural competitions to develop design proposals which included urban agriculture. The latter enabled us to estimate the yields resulting from urban agriculture and other low energy features (e.g. solar hot water and photovoltaics). Our overall aim was to make a robust case for urban agriculture underpinned by quantifiable environmental data and qualitative design studies (Viljoen and Bohn 2000).

The quantifiable arguments in relation to urban agriculture are primarily environmental and economic, with a developing strand linking landscape to psychological and public health benefits (Viljoen and Bohn 2005: 34-36).

The strongest environmental benefit of urban agriculture results from the reduction in food miles and therefore embodied energy and associated carbon dioxide emissions (Department for the Environment Farming and Rural Affairs 2005). If organic agriculture is practiced, the elimination of energy intensive artificial fertilizers makes a further contribution to reducing environmental impact.

In the context of peak oil and climate change

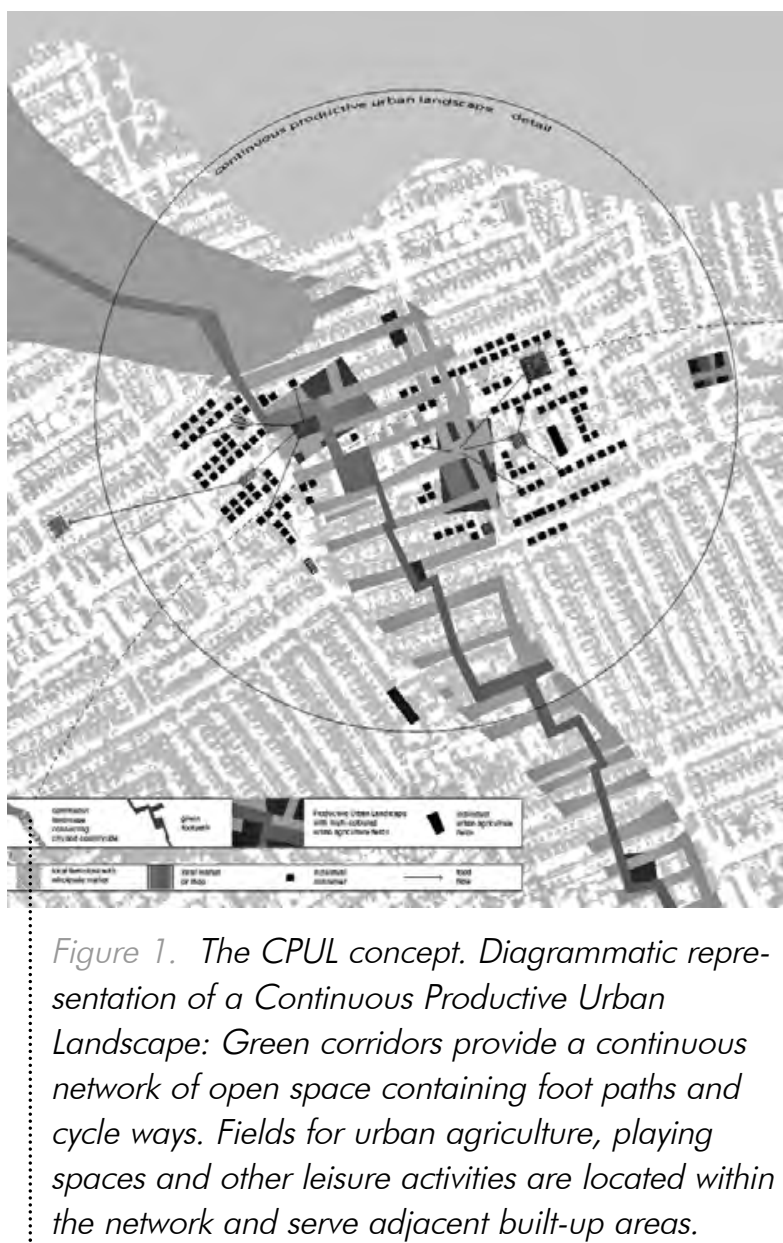

mitigation strategies, historic arguments made prior to the petrochemical era provide evidence for the advantages of locating fruit and vegetable production adjacent to urban areas. The writing of Johann von Thünen, first published in 1826 (Chisholm 1972: 20-32) deserves reevaluation.

Economic arguments for urban agriculture depend on a city's status within the global economy as the cost of urban land is a major issue. A new and inclusive planning approach is needed to justify the use of inner-urban open space for non-building activity. However, even in countries with high land value, this more complex approach to economic viability shows encouraging results: The UKbased New Economics Foundation, for example, estimated that every $£ 10$ spent with a local food initiative in the UK is worth $£ 25$ for the local area, compared with just $£ 14$ when the same amount is spent in a supermarket (New Economics Foundation 2001). Furthermore, if the cost of constructing urban agriculture sites is compared to the cost of other elements of infrastructure, for example roads, urban agriculture is about forty times less expensive. (Viljoen and Bohn 2005: 34-36).

Our design studies for sites in the UK have 

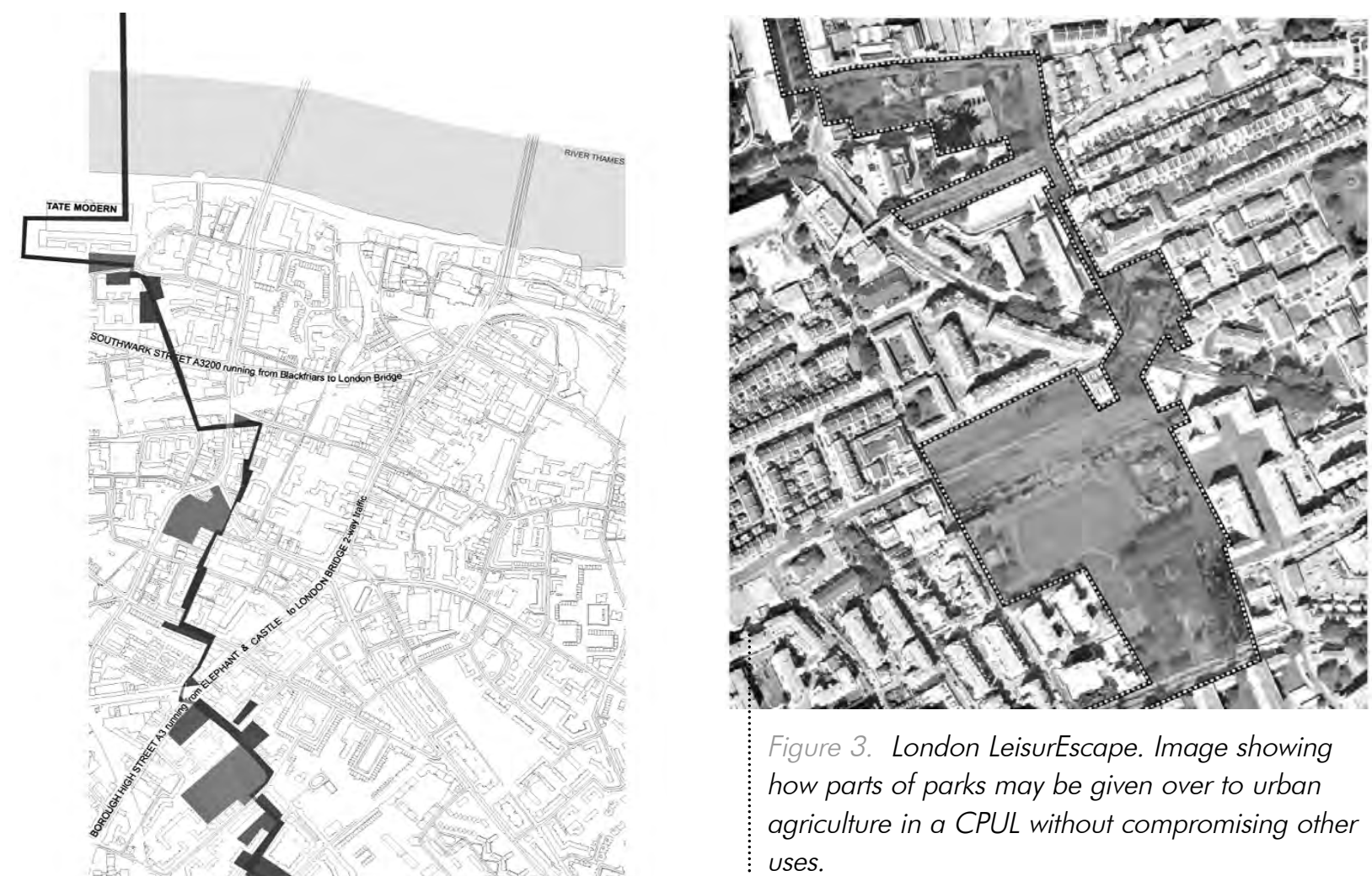

Figure 3. London LeisurEscape. Image showing how parts of parks may be given over to urban agriculture in a CPUL without compromising other uses.

indicated that there is potential for urban agriculture within most situations. Anecdotal evidence from organic practitioners in the UK suggests that yields equivalent to half of those achieved in Cuba are possible in the UK climate. In Cuba, it is estimated that urban agriculture provides about $60 \%$ of Cuban vegetable production (Bourque and Cañizares 2001) and about $30 \%$ of Havana's fruit and vegetable requirements (Murphy 1999). Based on our own design studies, we estimate that there is sufficient growing area available within urban areas in the UK so that, notwithstanding differences in climatic conditions, a similar contribution to fruit and vegetable requirements would be possible in the UK. If peri-urban agriculture (growing on the edge of the city) were included, then there is no reason for not further increasing this contribution. Such yields are significant. In every city, they would lead to reductions in $\mathrm{CO} 2$ emissions and to an increase in economic prosperity whilst, at the same time, improving the city's attractiveness and providing for urban lifestyle choices.

One major obstacle to the introduction of CPUL into cities is the potential soil contamination of sites reclaimed from uses such as brownfields, railway embankments, carparks or roads. Careful planning is necessary, as well as solutions which isolate food growing from the soil, either permanently or during the decontamination process. Examples for this are documented in places that 

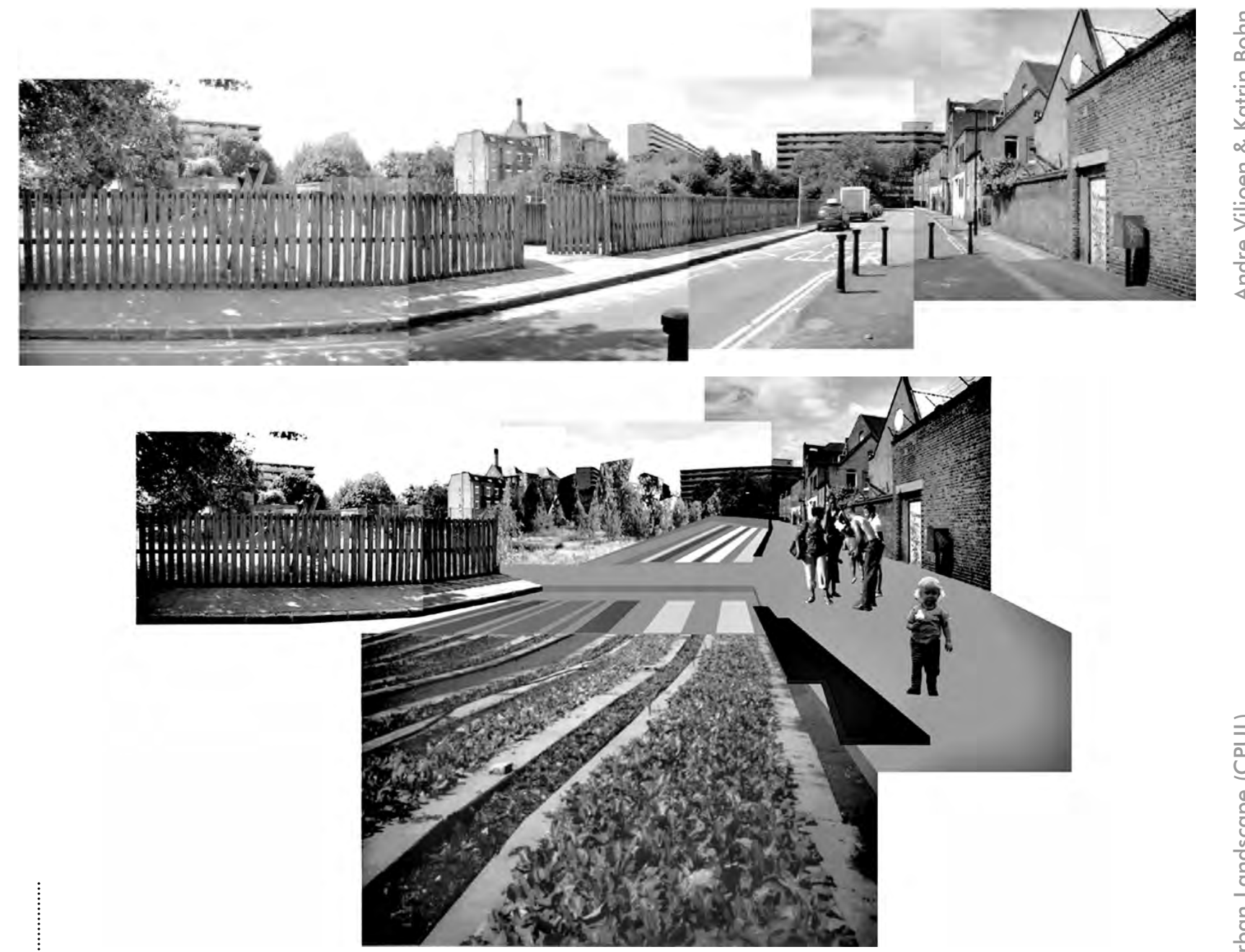

Figure 4-5. London LeisurEscape. Munton Road, London, before and after implementing a CPUL. In this proposal, the road, which is lightly used by vehicles, would be converted into an urban agricultural field surrounded by cycle and pedestrian ways.

practice urban agriculture and include, amongst others, the growing in raised beds, and various methods of soil cleansing such as the sealing off of toxic layers of soil, the replacement of topsoil or the reduction of toxins through planting (Thompson and Solvig 2000).

Our conclusion to this initial research was that urban agriculture could make a significant contribution to fruit and vegetable requirements, and that a case could be made for considering it as an essential element of sustainable infrastructure in existing and developing cities. This infrastructure

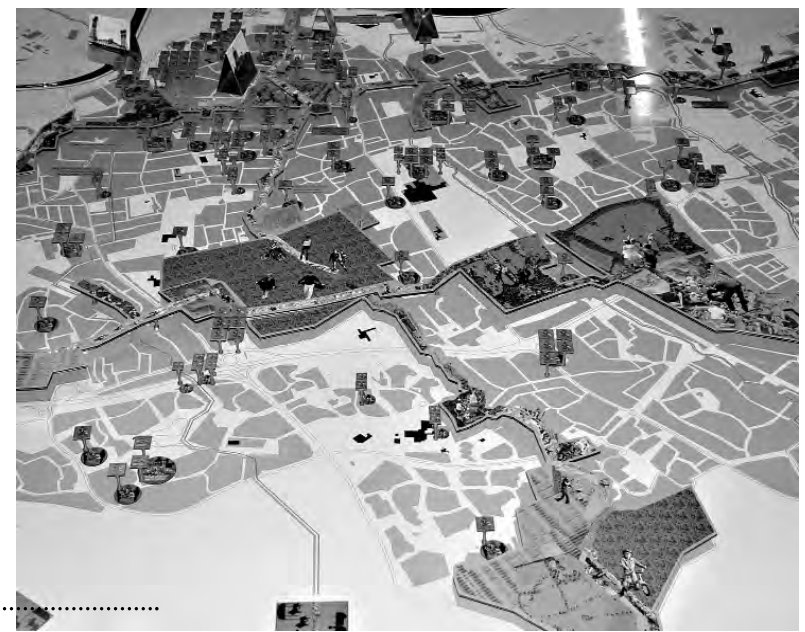

Figure 6. Middlesbrough CPUL. Opportunity Map developed as part of the UK Design Council's Designs of the Time (DOTT07) year-long urban farming project. During 2007, the population of Middlesbrough, the local authority and community organisations participated in urban agriculture projects across the town. Bohn \& Viljoen's proposal for a Middlesbrough CPUL shows the identified network of open spaces and indicates DOTTO7 urban farming sites (small square raised elements). 
would best be located within corridors of open space, forming a coherent overall landscape strategy, defined by us as a Continuous Productive Urban Landscape (CPUL) (Viljoen 2005).

\section{CUBA : LABORATORY FOR URBAN AGRICULTURE}

Cuba's extensive urban agriculture programme makes it an ideal place to learn about the pragmatics and possibilities associated with urban agriculture.

Urban agriculture was introduced to Cuba as a consequence of food shortages resulting from the collapse of the Soviet Union in 1989, when Cuba suffered a loss of $80 \%$ of its trade and all access to imported fuel (Cruz Hernández and Medina 2003). It is one of the features of the "Special Period" (post 1989), that has so far been retained and was, in 2000, officially incorporated as a permanent element in Havana's city plan (Cruz Hernández and Medina 2003). At the time of our last research visit to Havana in 2006, new urban agriculture sites continued to be established.

In 2004, a survey of planners and architects in two thirds of Havana's municipal planning offices indicated that $62 \%$ thought urban agriculture could be thought of as a permanent land use, with 55\% stating that it should not be replaced by more profitable land uses. Most respondents agreed that urban agriculture did not detract from the city's image and perceived it as an element influencing sustainability (Peña Diaz 2005).

Some urban planning professionals suggest that, as the economic conditions change, urban agriculture should gradually be moved to the outskirts of the city and be replaced by forms of ornamental urban planting (Premat 2005: 165). Public perception seems to distinguish between "working landscape", such as urban agriculture, and "leisure landscape" where planting follows a brief that clearly excludes a use for anything but visual or practical comfort. "This correlation of ornamental and noncomestible with greening is significant, as is the consistency in this usage within the sector" (Premat 2005: 166). By contrast, staff associated with urban agriculture in Cuba's Ministry of Agriculture have noted the need to convince planners that "lettuce plants could be as decorative as flowers" (Premat 2005: 168).

Despite an awareness of urban agriculture's economic role within Havana, there are no indica- tions of practical attempts to combine it with other city planning strategies such as sustainable transport, density manipulation or urban sustainability concepts. Within the framework of planning instruments in place, urban agriculture currently remains an isolated component of Havana's planned and perceived urban fabric.

If the case is to be made for the widespread adoption of urban agriculture, it will be necessary to demonstrate, communicate and publicise the qualities which it brings to cities beyond the production of fruit and vegetables.

\section{THE PLACING AND PERCEPTION OF CPUL WITHIN CONTEMPORARY CITIES}

To explore the design characteristics of urban agriculture, we selected with Cuban colleagues ten urban agriculture sites for detailed investigation. By comparing and assessing the chosen sites, characteristics related to spatial qualities, function and perception could be named and design strategies developed to accommodate and utilize these in urban planning in a more conscious way.

The severe economic difficulties during the period after 1989 resulted in urban agriculture sites being located in towns and cities using mainly pragmatic criteria; "design" in the aesthetic or formal sense could not be considered. The location of sites was determined largely by the most efficient growing and distribution of crops.

This means that urban agriculture fields are now found in a great variety of locations and within a wide range of contexts, providing a unique opportunity for judging their spatial characteristics and relationships with the built environment and people. A decision was made to limit the study to "organoponicos", these being the most replicable model of high-yield, organic urban agriculture sites. Organoponicos can be defined as commercially viable high-yield urban market gardens, cultivated using essentially organic methods. They typically provide employment for five or six workers, and range in size from a few hundred square meters to a few hectares.

For each of the ten selected sites, surveys recorded the site layout, naming spatial qualities and the use of materials. As with many aspects of urban agriculture, these studies indicated a range of characteristics for different sites, which may best be summarised as indicating the degree of variety 


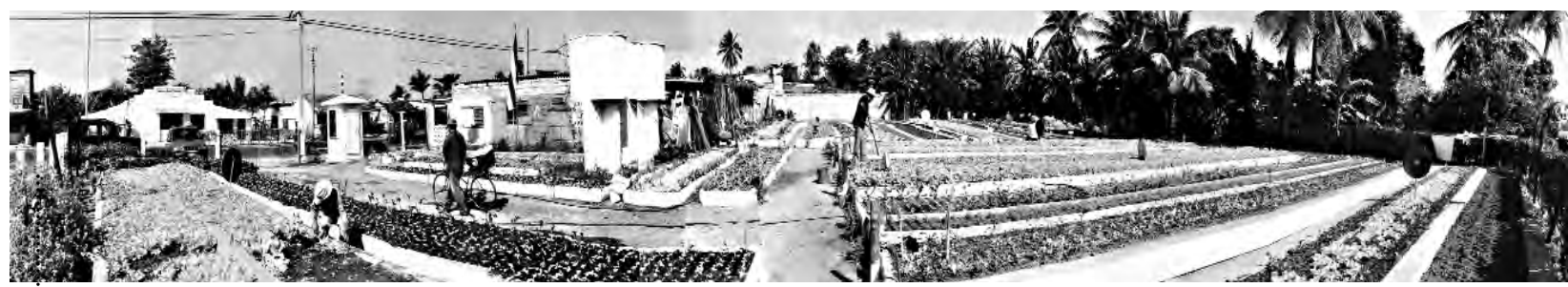

Figure 7. Pueblo Grifo Viejo in Cienfuegos, Cuba. A typical small organoponico.

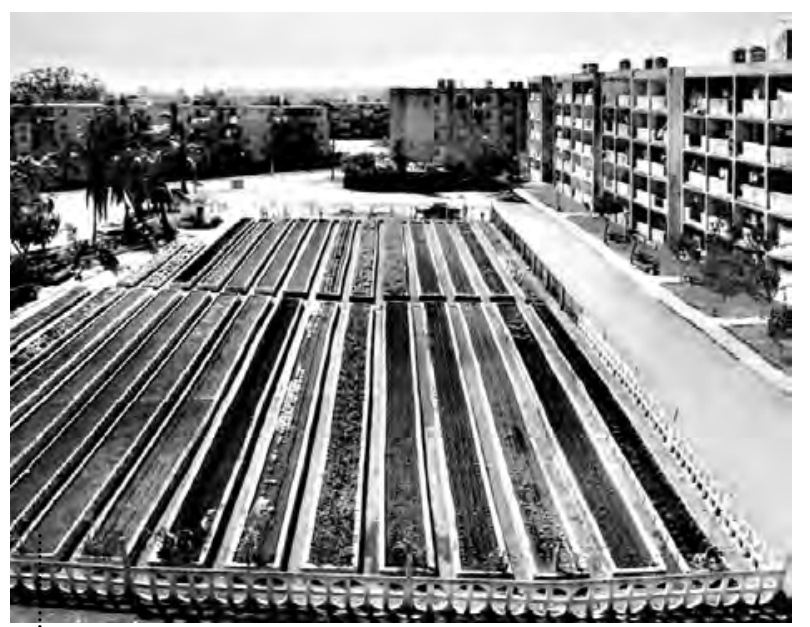

Figure 8. Pueblo Grifo Nuevo in Cienfuegos, Cuba. A typical medium-sized organoponico.

generated when a standardised approach has to adapt to different contexts.

The most important spatial and use variations relate either to physical characteristics of the sites or to patterns of use and occupation (Viljoen 2005: 147-191):

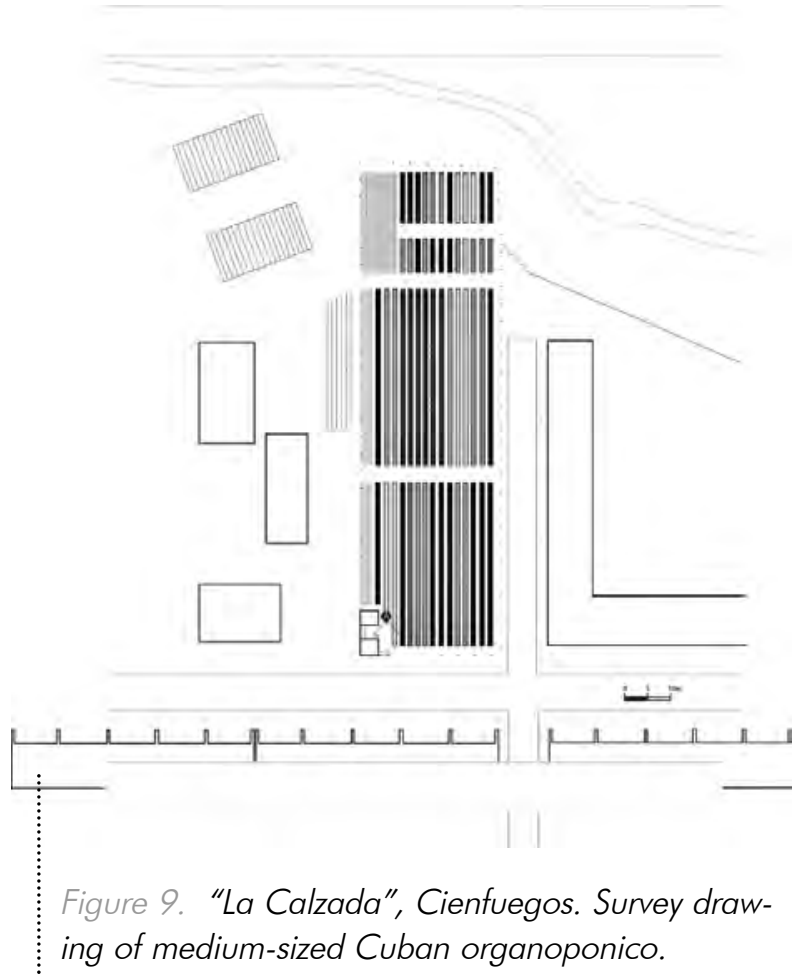

\section{Enclosure:}

All sites had some form of enclosure, the physical characteristics of which had a strong impact on how the space was read within the city. Boundaries varied in their thickness and transparency, altering the sites' character between roomlike or field-like territories, which, in turn, determined potential other uses of space within that urban agriculture field, or along its edge. In all cases, the sites had strong visual presence, and in some cases this only became evident when viewing the sites from above, for example from the upper floors of adjacent buildings.

\section{Multiple Use:}

In some cases, sites had developed specific uses beyond the growing of food, such as outdoor classrooms, picnic sites, sales points and health advice centres. Most of these uses required a dedicated area which further enriched the organoponico's contribution to the city and encouraged a sense of ownership beyond that of the urban farmers'.

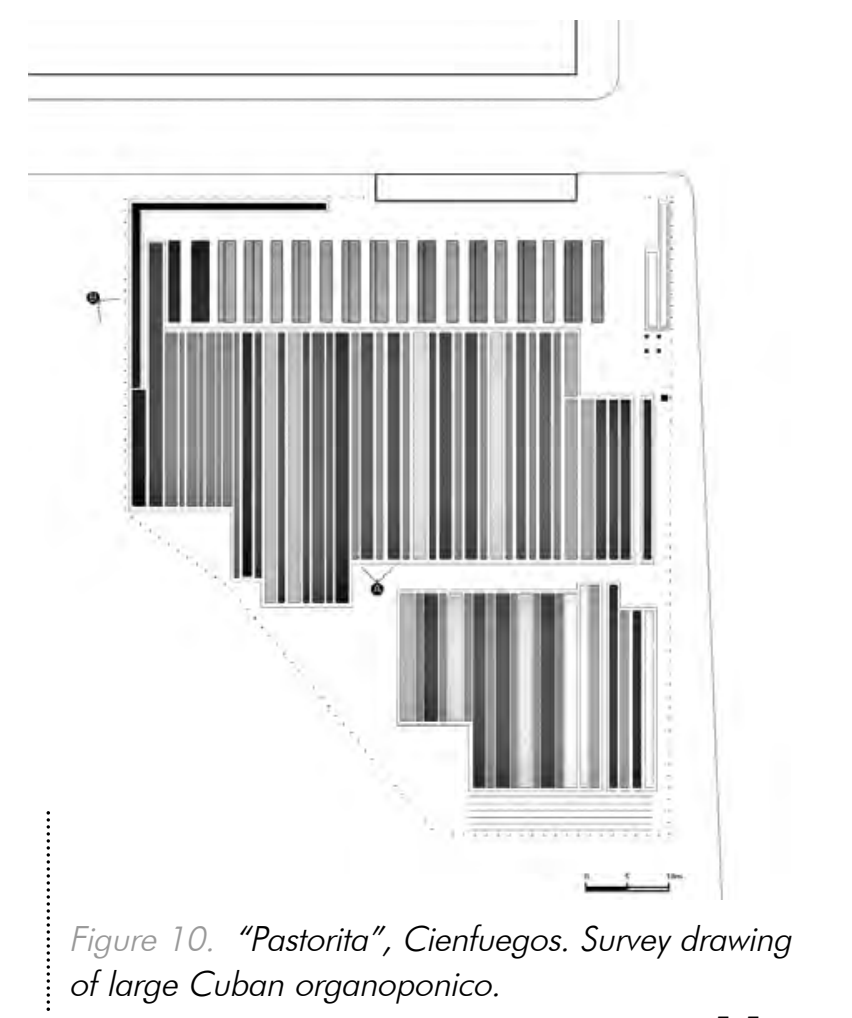



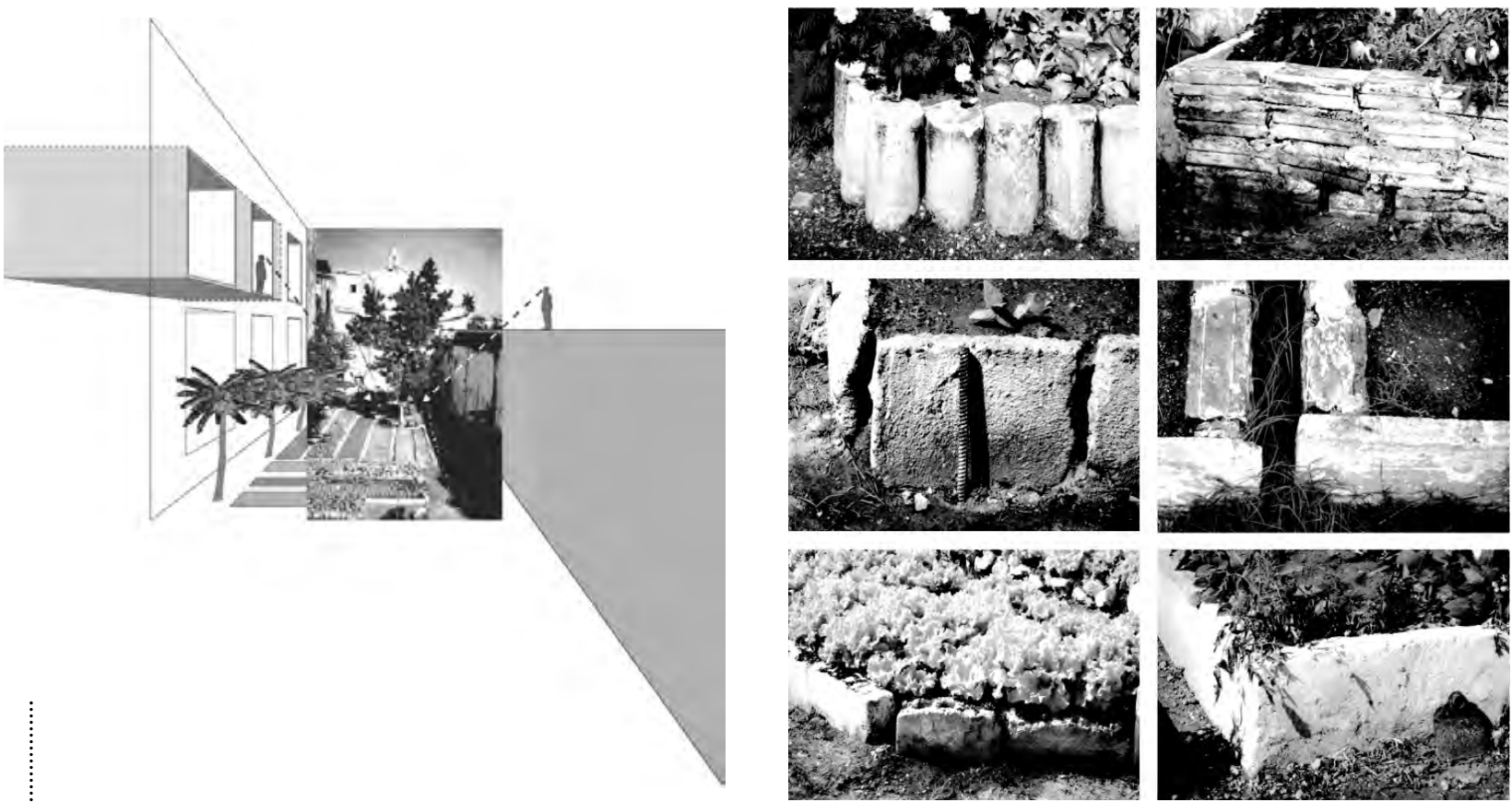

Figure 7 7-72. Organoponics can often become a shared visual experience for a number of different people / buildings, effectively expanding their sphere of influence (Fig 11). They offen display a great deal of variety, in this case of enclosing materials, within an otherwise strictly ordered system (Fig 12).

\section{Shared Visual Facility:}

Urban agriculture fields are often visible from a number of surrounding windows and vantage points and, as such, provide people with a shared visual resource. If six apartments overlook an urban agriculture field, it is as if the open space's value is multiplied by six. This connection between residents and farmers is important, as it links the public with the natural systems that sustain life. It also provides a sense of open space within a dense city which is sought by many people.

\section{Linking Device:}

The linearity of growing beds provide physical and optical links across fields and larger territories, and assist in unifying and giving coherence to potentially disparate parts of the urban fabric.

\section{Sculptural Quality:}

Relationships between the eye level of an observer, undulations in topography and the horizontality of growing beds establishes an optical effect that accentuates local topography and reminds viewers of the earth's surface. Space becomes animated in three dimensions, the topography is marked and measured.

\section{Incremental Occupation:}

Where organoponicos are located on peripheral areas or areas without pressure on available land, they frequently include patches of open ground, which suggest temporary uses such as celebratory events, like a circus visit or a wedding reception.

\section{CROSSING BOUNDARIES : VISUALIZING PRODUCTIVE LANDSCAPE}

How is urban agriculture perceived? Some of the quantifiable benefits arising from the localization of food production, for example the reduction in greenhouse gas emissions from reduced food miles, are invisible and intangible. Implementing change will require a shift in opinion which is cultural rather than economic or environmental. This poses the further question about how to represent and envision the urban qualities associated with CPUL. Some of the tasks relate to generating a debate about open urban space, some to raising awareness about food and its potential for generating convivial social activity. All of them require responses that must not only be easily understandable by the public, but also actively engage it in a collaborative urban design process.

Our observations were that artists tend to work in a very direct way with their public, creating powerful experiences that are both visceral and 

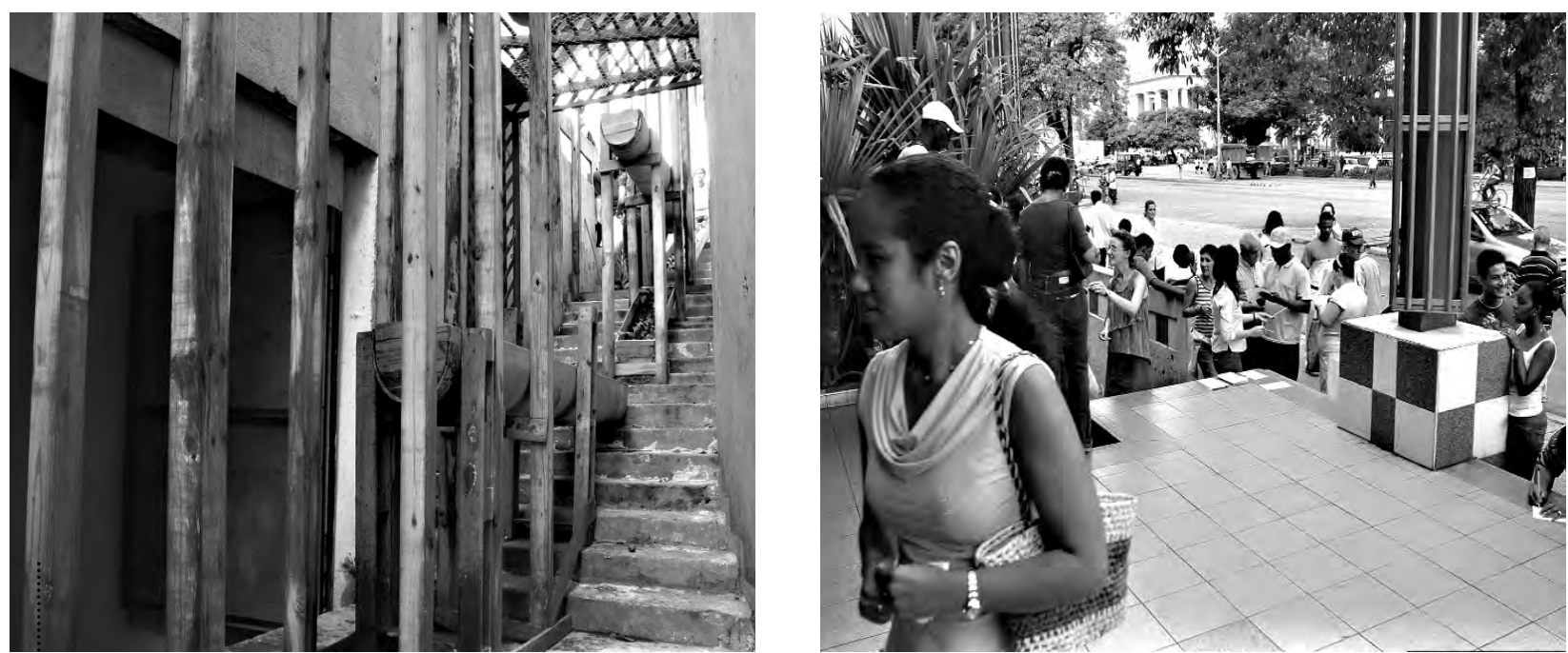

Figure 13-74. The exhibition Utilitarian Dreams Havana, during which Cuban and UK artists and architects presented work exploring the urban environment. Fig 13: Micro Organoponico. Installation by the authors which acted as exhibition entrance marker and within which lettuce grew. All elements for the installation, soil, crops, and growing channels were loaned from an adjacent organoponico. Fig 14: Finding Parque Lenin. Installation by the authors engaging members of the public, here outside the exhibition venue completing questionnaires.

intellectual and from which design and planning professionals can learn much. We embarked on a third strand to our research: to visualise CPUL with the help of exhibition and installation work.

Contemporary artistic practice as recorded in "Less - alternative living strategies" (Scardi 2006) may suggest a way forward. Placed somewhere between social activism, performance, education and installation, "Less" includes the work of several artist who practice in the public realm, or include the public directly within their art works. Particularly innovative work is being produced by the Swedish artists and organic farmers "Kultivator" who aim to "point out the parallels between provision production (food) and art practice" (Kultivator 2007). Equally, the Dutch artist Debra Solomon runs the much visited "Culiblog" blog dedicated to food and environment (Culiblog 2007).

Apart from linking our work to art projects such as the above, one focus became to challenge the public perception of CPUL and urban agriculture by finding similarities with accepted ways of seeing as exemplified by the notion of urban ornament.

Although not contrived to be ornamental, ornament is inherent within the visual patterns resulting from the functional layout of typical Cuban organoponicos. In this context, it is interesting to review the work of British artist Tom Phillips. Phillip's summary treatise "The Nature of Ornament" describes nature as the source of ornamentation and ornament as providing a vital connection with the surrounding natural environment (Phillips 2002):

"8.

Such universality (of ornament) is made possible by (its) relatively small generative syntax.

9.

These syntactical elements are all paraphrases of nature; stripe, hatching, dot and the whole treasury of primal signs are all present in nature.

48.

It stores our knowledge of the principles of growth and form (forking, branching, spiral) and diagramatises our experience."

This close correspondence between a visual description of organoponicos and the characteristics of ornament led Tom Phillips to describe urban agriculture practiced in Cuba as "organic ornament". It is our view that this is an important observation. Developing and stimulating similar ideas within public discourse will be significant in convincing people that urban agriculture can contribute positively to a city in many ways.

In our own work, we want to communicate to an audience what the experience of spaces associated with urban agriculture would be like.

Katrin Bohn has used video recording to document and describe particular spatial conditions found within inner-urban space in Brighton and Havana, in each case choreographing a walk to show how open space may mediate boundaries or be obstructed by physical and non-physical barriers. By framing views, the video allowed the view- 


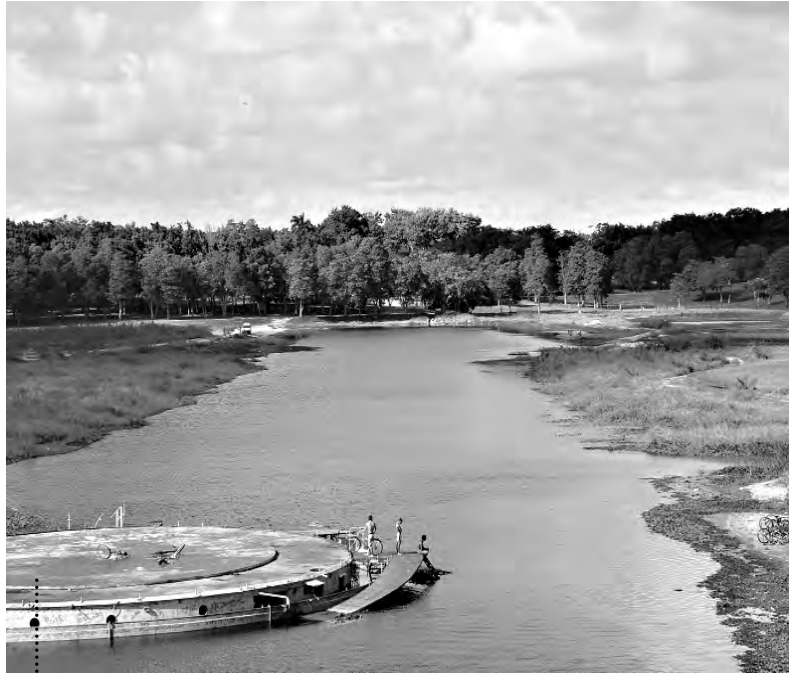

Figure 75-76. Parque Lenin Havana. November 2006.

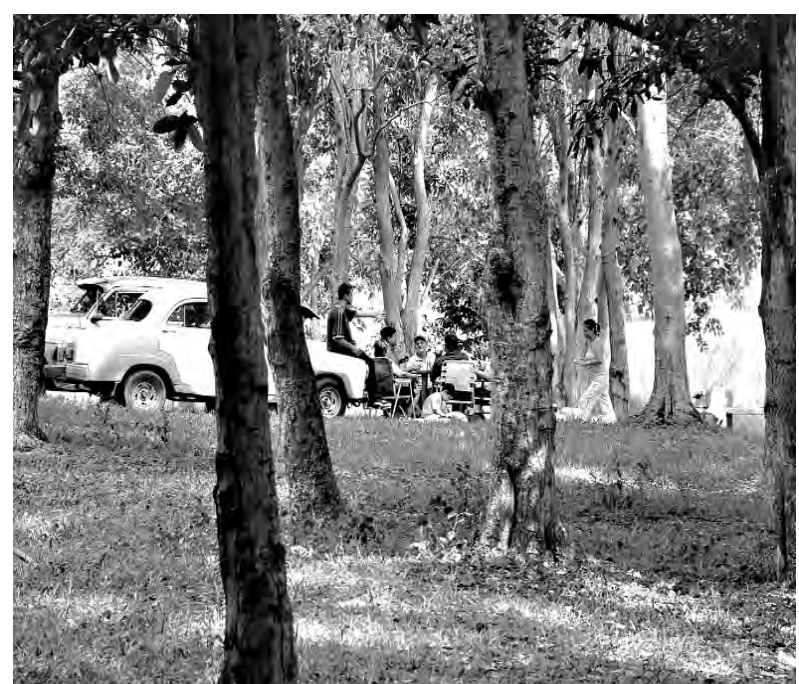

favourite destination until the fuel crisis of 1989, when visitor numbers dropped due to lack of transportation. By 2006, most attractions had deteriorated seriously. Restoration started in 2005.

The exhibit "Finding Parque Lenin" centred on a proposal by Bohn \& Viljoen for a CPUL connecting inner Havana to Parque Lenin. As part of this, visitors to the exhibition were invited to complete a questionnaire about attitudes to Parque Lenin and open space in the city. No question specifically referred to urban agriculture with the aim of finding out if respondents would make unprompted connections between this, the qualities found in Parque Lenin and Havana's more traditional open urban space such as public parks, gardens and squares.

Of the 268 members of the public who completed the questionnaire, only 8 had not visited Parque Lenin. The bad state of public transport (due to Cuba's fuel shortage) was the respondents' main complaint when explaining the lower frequency of recent visits. Notwithstanding this, $69 \%$ of respondents had visited during the last 6 years. The attraction of Parque Lenin seems unbroken since its opening in the early Seventies and respondents are clear, that they would like to visit the park more (about $80 \%)$.

The overwhelming majority of people visited for one of two reasons, either to enjoy the open space, beauty of nature, vegetation etc. or to enjoy the outdoor leisure activities on offer. The majority of respondents thought of the park as either open, green landscape or as facilitator of leisure activity. This memory is confirmed in answers to a question about inner-city space that reminded respondents of Parque Lenin: the spaces most often referred to 
are those that have the appearance of traditional urban parks or of "natural" landscape (Parque Almendares [walking landscape alongside a small river], Bosque de la Habana [woodland], Metropolitan Park [grassy urban park]). The next most quoted spaces are those that contain leisure attractions (Expocuba [national exhibition centre], Inflatable Park [amusement park]).

Two thirds of all respondents said they would like to have Parque Lenin within the city, giving reasons falling into two broad categories: quantitative (environmental and transport/traffic concerns) and qualitative ("would be great!").

While the general positive attitude to being in open space, to outdoor leisure activities and their easy reach, support the CPUL concept, none of the respondents said that urban agriculture sites reminded them of qualities associated with Parque Lenin. This has been disappointing, but not surprising as it reinforces earlier findings of Premat in 2005. Even in a city and country with the most integrated urban agricultural sites that nourish the population, these spaces are not appreciated as landscape. And whilst a 'coffee shop' (named in one questionnaire) qualifies as space of similar character to Parque Lenin, an organoponico does not.

We can identify various reasons for this omission of urban agriculture landscape from the public perception of quality open space. It is evident, that the design of spaces for urban agriculture has to compliment both, the needs of the urban farmer and those characteristics of open space that people perceive as desirable. These need to be addressed prior to the establishment of any CPUL:

1) utility landscape vs ornamental landscape

In our survey case, it has proven wrong to assume that exposure to urban agriculture increases its acceptance. Equally, well-known environmental arguments in favour of urban agriculture do not outweigh a long-grown viewing habit that attaches the value of beauty to a familiar range of open spaces.

2) working landscape vs leisure landscape

Perhaps urban agriculture sites are perceived a utilitarian landscape, negatively associated with a form of living and producing practiced by the parents' generation rather than being a forward looking aspiration. It will be important to study national cultural characteristics, as there might be substantially different perceptions in older and younger industrialised as well as agrarian countries.

3) unusable urban landscape vs usable urban landscape
Urban agriculture sites are not recognised as accessible, as part of a usable urban landscape.

There are several directions to progress this research in relation to the public perception of urban agriculture and with the aim of developing strategies to overcome practical obstacles to implementing it:

One research area is to study in detail what made/makes the experiences of those who enjoyed Parque Lenin's landscape so positive, ie. how to replicate the liberating experience of walking, picnicking, making love, seeing, observing, hanging out (all mentioned several times in the questionnaires)... Another is to establish the degree of diversion that people are willing to accept when referring to a landscape's beauty, ie. to study how different the spaces that reminded of Parque Lenin are from the actual Parque Lenin.

\section{CONCLUSION}

A strong environmental case can be made for urban agriculture as an essential element of sustainable infrastructure. Concepts like Continuous Productive Urban Landscape (CPUL) provide design strategies capable of giving coherence to the infrastructural and qualitative aspects of urban agriculture.

If urban agriculture is to be widely adopted its functions in addition to environmental sustainability, such as urban ornament, require articulation.

In Cuba, Havana provides an example where planning professionals adopted urban agriculture as a legitimate urban land use. Notwithstanding this, urban agriculture's long term role in the city remains uncertain as it is not yet seen as an equivalent to other forms of urban greening or as valuable as potential commercial development.

An initial survey of public attitudes to open space within Havana indicates that urban agriculture is not thought of in the same way as traditional park-like landscapes. The survey shows an appreciation of easily accessible parks which include provision for a variety of different outdoor leisure activities. The latter supports the principals of CPUL, which include mixed land use activities, adjacency to the built environment and networks for walking and cycling.

A major area for future research has been identified as the need to explore and communicate 
to the public and built environment professionals the many qualitative benefits of urban agriculture challenging its perception as a "non-urban landuse" and "of lesser beauty". Much can be learnt about how to communicate such issues from particular fields of contemporary art practice addressing spatial and environmental, urban and social issues, often by engaging with the public through installation and event.

\section{ACKNOWLEDGEMENTS}

Our work in Havana was undertaken with the support and collaboration of Dr. Arq. Jorge Peña Díaz, Director del Centro de Estudios Urbanos de La Habana Facultad de Arquitectura CUJAE and with assistance from the Fundación Antonio Núñez Jiménez de la Naturaleza y el Hombre. Research has been supported by the Royal Institute of British Architects (RIBA), The British Council, Triangle Arts Trust and the University of Brighton.

\section{REFERENCES}

ALLEN S. 1996, Infrastructural Urbanism, "Performance Notations: Barcelona ZAL," Scroope 9, University of Cambridge: $71-9$

BOURQUE M., and CAÑIZARES K. 2001, Urban Agriculture in Havana, Urban Agriculture Magazine 1(1): 27-29.

CHISHOLM M. 1972, Rural Settlement and Land Use, Hutchinson \& Co, London, United Kingdom: 20-32.

CULIBLOG. 2007, Available from http://www.culiblog.org/ [Accessed 28,4,08].

CRUZ HERNÁNDEZ M.C., and MEDINA R.S. 2003, Agriculture in the City: A key to Sustainability in Havana, Cuba, lan Randle Publishers, Kingston, Jamaica.

DEPARTMENT FOR THE ENVIRONMENT FARMING AND RURAL AFFAIRS (UK). 2005, , The Validity of Food Miles as an Indicator of Sustainable Development, Final Report for DEFRA, 56254 (7), AEA Technology, Oxford, United Kingdom.

KULTIVATOR. 2007, Info [online] Available from http://www.kultivator.org/info.html [Accessed 28/4/08].

MURPHY C. 1999, "Cultivating Havana: Urban Agriculture and food security in the years of Crisis," Development Report 12, Food First, Institute of Food and Development Policy, Oakland, California.
NEW ECONOMICS FOUNDATION. 2001, NEF survey (online) Available from:

http://www.neweconomics.org/gen/m6_i121_news.aspx [accessed 21/11/07].

PEÑA DIAZ J. 2005, Contribución a la integración de la agricultura urbana en el Plan general de ordenamiento territorial de municipios de La Habana, Unpublished.

PHILIPS T. 2002, The Nature of Ornament: A summary Treatise, Architectural Review, 213 (1274).

PREMAT A. 2005, 'Moving between the Plan and the Ground', In Mougeot, L. J. A. (ed) Agropolis: The Social, Political and Environmental Dimensions of Urban Agriculture, Earthscan, London, United Kingdom.

SCARDI G. (ed) 2006, Less: Alternative Living Strategies, 5 Continents Editions srl, Milano, Italy.

THOMPSON J. W., and SORVIG K. 2000, Sustainable landscape construction, Island Press, Washington DC, USA.

VILJOEN A, and BOHN K. 2000, "Urban Intensification and the Integration of Productive Landscape," Proceedings of the World Renewable Energy Congress VI, Part 1, Pergamon Press, Oxford, United Kingdom.

VILJOEN A, and BOHN K. 2005, "Continuous Productive Urban Landscapes : urban agriculture as an essential infrastructure," The Urban Agriculture Magazine 15: 34-36.

VILJOEN A. (ed.) 2005, Continuous Productive Urban Landscapes CPULs: designing urban agriculture for sustainable cities, Architectural Press, Oxford, United Kingdom.

WACKERNAGEL M., and REES W. 1996, Our ecological footprint: reducing human impact on the earth, New Society Publishers, Canada

YOKOHARI M. YUJOBO S., and SHINOZAWA K. (ed.) 1995, Process Architecture 127: ecological landscape planning, Process Architecture Co, Tokyo, Japan.

\section{Authors' Addresses:}

Andre Viljoen \& Katrin Bohn

Bohn \& Viljoen Architects

School of Architecture and Design

University of Brighton

a.viljoen@brighton.ac.uk 